\title{
Estimation of crop water requirements: extending the one-step approach to dual crop coefficients
}

\author{
J. P. Lhomme ${ }^{1}$, N. Boudhina ${ }^{1,2}$, M. M. Masmoudi ${ }^{2}$, and A. Chehbouni ${ }^{3}$ \\ ${ }^{1}$ Institut de Recherche pour le Développement (UMR LISAH), 2 Place Viala, 34060 Montpellier, France \\ ${ }^{2}$ Institut National Agronomique de Tunisie (INAT), 43 Avenue Charles Nicolle, 1082 Tunis, Tunisia \\ ${ }^{3}$ Institut de Recherche pour le Développement (UMR CESBIO), 18 Avenue Edouard Belin, 31401 Toulouse, France \\ Correspondence to: J. P. Lhomme (jean-paul.lhomme@ird.fr)
}

Received: 15 April 2015 - Published in Hydrol. Earth Syst. Sci. Discuss.: 18 May 2015

Accepted: 19 July 2015 - Published: 30 July 2015

\begin{abstract}
Crop water requirements are commonly estimated with the FAO-56 methodology based upon a two-step approach: first a reference evapotranspiration $\left(\mathrm{ET}_{0}\right)$ is calculated from weather variables with the Penman-Monteith equation, then $\mathrm{ET}_{0}$ is multiplied by a tabulated crop-specific coefficient $\left(K_{\mathrm{c}}\right)$ to determine the water requirement $\left(\mathrm{ET}_{\mathrm{c}}\right)$ of a given crop under standard conditions. This method has been challenged to the benefit of a one-step approach, where crop evapotranspiration is directly calculated from a Penman-Monteith equation, its surface resistance replacing the crop coefficient. Whereas the transformation of the twostep approach into a one-step approach has been well documented when a single crop coefficient $\left(K_{\mathrm{c}}\right)$ is used, the case of dual crop coefficients ( $K_{\mathrm{cb}}$ for the crop and $K_{\mathrm{e}}$ for the soil) has not been treated yet. The present paper examines this specific case. Using a full two-layer model as a reference, it is shown that the FAO-56 dual crop coefficient approach can be translated into a one-step approach based upon a modified combination equation. This equation has the basic form of the Penman-Monteith equation but its surface resistance is calculated as the parallel sum of a foliage resistance (replacing $K_{\mathrm{cb}}$ ) and a soil surface resistance (replacing $K_{\mathrm{e}}$ ). We also show that the foliage resistance, which depends on leaf stomatal resistance and leaf area, can be inferred from the basal crop coefficient $\left(K_{\mathrm{cb}}\right)$ in a way similar to the MattShuttleworth method.
\end{abstract}

\section{Introduction}

The well-known FAO-56 publication on crop evapotranspiration (Allen et al., 1998) is the outcome of a revision project concerning a previous publication (FAO-24) on the same subject (Doorenbos and Pruitt, 1977). In FAO-56 the current guidelines for computing crop water requirements are presented. Two different ways of calculating crop evapotranspiration are retained and detailed: the single crop coefficient and the dual crop coefficient. In the single crop coefficient approach, crop evapotranspiration under standard conditions is calculated as

$\mathrm{ET}_{\mathrm{c}}=K_{\mathrm{c}} \mathrm{ET}_{0}$.

$\mathrm{ET}_{0}$ is the reference crop evapotranspiration determined from the Penman-Monteith equation and accounts for weather conditions. $K_{\mathrm{c}}$ is the crop coefficient, in which crop characteristics are incorporated and which is supposed to be largely independent of weather characteristics, enabling its transfer from one location to another. In the dual crop coefficient approach, $K_{\mathrm{c}}$ is split into two separate coefficients: one represents crop transpiration $K_{\mathrm{cb}}$ (it is called basal crop coefficient) and the other soil evaporation $K_{\mathrm{e}}$. Thus, crop evapotranspiration under standard conditions is calculated as

$\mathrm{ET}_{\mathrm{c}}=\left(K_{\mathrm{cb}}+K_{\mathrm{e}}\right) \mathrm{ET}_{0}$.

Whereas the values of $K_{\mathrm{cb}}$ are tabulated in FAO-56 and easily accessible, those of $K_{\mathrm{e}}$ are the result of a relatively complex and mainly empirical procedure summarized in Appendix A (Allen et al., 1998; Allen, 2000). The basal crop coefficient 
$K_{\mathrm{cb}}$ is a characteristic value of a given crop, obtained under standard conditions and transferable as such, whereas the value of $K_{\mathrm{e}}$ should be adjusted to the specific conditions under which the crop is grown.

The FAO-56 methodology (single or dual crop coefficients) is commonly called the two-step approach (Shuttleworth, 2007) because $\mathrm{ET}_{0}$ is first calculated from weather variables and then empirically adjusted using crop-specific coefficients. The empirical character of the FAO methodology has been criticized by many authors for various reasons (Wallace, 1995). Firstly, if crop coefficients mainly depend on crop characteristics, they also vary somewhat with weather variables. This means that transferring their values into locations where weather conditions significantly differ from those under which they were initially determined is risky (Katerji and Rana, 2014). FAO-56 specifies that the tabulated values of crop coefficients are those corresponding to a sub-humid climate and should be modified for more humid or arid conditions according to an empirical formula. Secondly, the origins of $K_{\mathrm{c}}-K_{\mathrm{cb}}$ values proposed in FAO-56 are not completely clear: they sometimes appear as a compromise between contradictory data, which makes them subject to caution (Doorenbos and Pruitt, 1977; Shuttleworth and Wallace, 2009; Katerji and Rana, 2014). Thirdly, the relatively complex and mainly empirical procedure to determine the soil evaporation coefficient $K_{\mathrm{e}}$ is another serious issue (Rosa et al., 2012).

Consequently, many authors (e.g. Shuttleworth, 2007) have suggested that a better approach would consist in estimating $\mathrm{ET}_{\mathrm{c}}$ as $\mathrm{ET}_{0}$ : i.e. directly by means of the PenmanMonteith equation (Eq. 3), in which the canopy surface resistance $\left(r_{\mathrm{s}}\right)$ of a specific crop would play the same role as the crop coefficient $K_{\mathrm{c}}$.

$\mathrm{ET}_{\mathrm{c}}=\frac{1}{\lambda} \frac{\Delta\left(R_{\mathrm{n}}-G\right)+\rho c_{p} D_{\mathrm{a}} / r_{\mathrm{a}}}{\Delta+\gamma\left(1+\frac{r_{\mathrm{s}}}{r_{\mathrm{a}}}\right)}$.

The significance of each variable in Eq. (3) is given in the list of symbols (Table A1). This method is often called the one-step approach, compared to the FAO-56 two-step approach. Shuttleworth (2006) provided a theoretical background, called the Matt-Shuttleworth approach, to transform the currently available crop coefficients $\left(K_{\mathrm{c}}\right)$ into effective surface resistances $\left(r_{\mathrm{s}}\right)$ to be used with the Penman-Monteith equation. This method, which in principle only applies to the single crop coefficient approach, has been thoroughly examined and discussed by Lhomme et al. (2014) and Shuttleworth (2014).

Given that the familiar Penman-Monteith equation (Eq. 3) is only relevant when soil evaporation is negligible, the problem which arises from a theoretical standpoint is that the dual coefficient of the two-step approach (Eq. 2), which accounts for crop transpiration and soil evaporation, cannot be translated into the one-step approach. A physical model equivalent to the dual coefficient approach would be the one- dimensional two-source model designed for sparse crops by Shuttleworth and Wallace (1985) and revisited by Lhomme et al. (2012). Unfortunately, from an operational standpoint, the practical implementation of this two-source model can be hindered by its mathematical formalism, which is far more complex than the common Penman-Monteith equation. Following the idea of Wallace (1995), who stated that "the key to continued improvement in evaporation modelling is to attempt to simplify these complex schemes while still retaining their essential elements as far as possible", the article aims at showing that the two-source model of evaporation can be transformed into a Penman-Monteith type equation, where foliage transpiration resistance and soil evaporation resistance are included within a bulk surface resistance. Then, it will be shown that the transpiration resistance can be inferred from the basal crop coefficient of the dual approach in a way similar to the Matt-Shuttleworth approach. Numerical simulations will be performed to illustrate the advantages of this new form of the Penman-Monteith equation to estimate crop water requirements with a one-step approach.

\section{Theoretical background}

\subsection{A generalized form of the Penman-Monteith equation}

The so-called Penman-Monteith equation (Monteith, 1963, 1965) results from the combination of the convective fluxes emanating from the canopy with the energy balance. Introducing effective resistances within and above the canopy, the convective fluxes of sensible heat $(H)$ and latent heat $(\lambda E)$ can be written in the following way:

$$
\begin{aligned}
& H=\rho c_{p}\left(\frac{T_{\mathrm{c}}-T_{\mathrm{a}}}{r_{\mathrm{a}}+r_{\mathrm{a}, \mathrm{h}}}\right), \\
& \lambda E=\left(\frac{\rho c_{p}}{\gamma}\right)\left[\frac{e^{*}\left(T_{\mathrm{c}}\right)-e_{\mathrm{a}}}{r_{\mathrm{a}}+r_{\mathrm{c}, \mathrm{v}}}\right] .
\end{aligned}
$$

$T_{\mathrm{a}}$ and $e_{\mathrm{a}}$ represent the temperature and the vapour pressure at a reference height $\left(z_{\mathrm{r}}\right)$ above the canopy; $T_{\mathrm{c}}$ is the effective temperature of the canopy and $e^{*}\left(T_{\mathrm{c}}\right)$ is the saturated vapour pressure at temperature $T_{\mathrm{c}}$ (the poor definition of $T_{\mathrm{c}}$ is not a key issue since it is eliminated in the final combination equation); $r_{\mathrm{c}, \mathrm{v}}$ is the effective canopy resistance for water vapour (which includes air and surface resistances within the canopy) and $r_{\mathrm{a}, \mathrm{h}}$ is that for sensible heat (which includes only air resistances). Both resistances should be logically added to the aerodynamic resistance above the canopy $\left(r_{\mathrm{a}}\right)$ calculated between the mean source height $\left(z_{\mathrm{m}}\right)$ and the reference height $\left(z_{\mathrm{r}}\right)$. In the common Penman-Monteith equation, the air resistances within the canopy $\left(r_{\mathrm{a}, \mathrm{h}}\right.$ or the air component of $r_{\mathrm{c}, \mathrm{v}}$ ) are neglected or assumed to be incorporated into the aerodynamic resistance $r_{\mathrm{a}}$. The combination of Eqs. (4) and (5) with the energy balance equation 
$\left(R_{\mathrm{n}}-G=H+\lambda E\right)$ results in the following equation:

$\lambda E=\frac{\Delta\left(R_{\mathrm{n}}-G\right)+\rho c_{p} D_{\mathrm{a}} /\left(r_{\mathrm{a}}+r_{\mathrm{a}, \mathrm{h}}\right)}{\Delta+\gamma\left(\frac{r_{\mathrm{a}}+r_{\mathrm{c}, \mathrm{v}}}{r_{\mathrm{a}}+r_{\mathrm{a}, \mathrm{h}}}\right)}$,

where $D_{\mathrm{a}}$ is the vapour pressure deficit at reference height and $\Delta$ is the slope of the saturated vapour pressure curve at air temperature.

As thoroughly explained in Lhomme et al. (2012, Sect. 4), the within-canopy resistances $\left(r_{\mathrm{a}, \mathrm{h}}\right.$ and $\left.r_{\mathrm{c}, \mathrm{v}}\right)$ can be interpreted using a two-layer representation of canopy evaporation, which takes into account foliage and soil contributions, as visualized in Fig. 1. From a theoretical standpoint, these effective resistances should be calculated as the parallel sum of the component resistances expressed per unit area of land surface: $r_{\mathrm{a}, \mathrm{h}}$ is the parallel sum of $r_{\mathrm{a}, \mathrm{f}, \mathrm{h}}$ (bulk boundary-layer resistance of the foliage for sensible heat) and $r_{\mathrm{a}, \mathrm{s}}$ (air resistance between the substrate and the canopy source height); $r_{\mathrm{c}, \mathrm{v}}$ is the parallel sum of $r_{\mathrm{s}, \mathrm{f}}+r_{\mathrm{a}, \mathrm{f}, \mathrm{v}}$ and $r_{\mathrm{s}, \mathrm{s}}+r_{\mathrm{a}, \mathrm{s}}$ with $r_{\mathrm{s}, \mathrm{f}}$ the bulk stomatal resistance of the foliage, $r_{\mathrm{s}, \mathrm{s}}$ the substrate resistance to evaporation and $r_{\mathrm{a}, \mathrm{f}, \mathrm{v}}$ the bulk boundary-layer resistance of the foliage for water vapour. Applying these formulations, however, does not allow the bulk canopy resistance for water vapour $\left(r_{\mathrm{c}, \mathrm{v}}\right)$ to be separated into two resistances in series: one for the air and the other for the surface. Consequently, the simple ratio of a surface resistance to an air resistance cannot appear in the denominator of Eq. (6), as in the common formalism of the Penman-Monteith equation (Eq. 3). Yet, this simple ratio is very convenient and useful from an operational standpoint because it allows separating the biological component of the canopy $\left(r_{\mathrm{s}}\right)$ from the aerodynamic one $\left(r_{\mathrm{a}}\right)$. Nevertheless, this simple ratio and the common form of the Penman-Monteith equation can be retrieved from its generalized form (Eq. 6) by means of a simple assumption, which consists in splitting the effective canopy resistance for water vapour $\left(r_{\mathrm{c}, \mathrm{v}}\right)$ into two bulk resistances put in series: one representing the transfer through the surface components $\left(r_{\mathrm{s}, \mathrm{v}}\right)$ and the other the transfer in the air within the canopy $\left(r_{\mathrm{a}, \mathrm{v}}\right)$ :

$r_{\mathrm{c}, \mathrm{v}}=r_{\mathrm{s}, \mathrm{v}}+r_{\mathrm{a}, \mathrm{v}}$.

This procedure is not sound from a strict physical standpoint, but the numerical simulations performed below will show that it constitutes a fairly good approximation. Assuming the component resistances within the canopy that act as parallel resistors and the bulk boundary-layer resistances of the foliage for sensible heat and water vapour to be equal $\left(r_{\mathrm{a}, \mathrm{f}, \mathrm{h}}=r_{\mathrm{a}, \mathrm{f}, \mathrm{v}}=r_{\mathrm{a}, \mathrm{f}}\right)$, the bulk air and surface resistances can be expressed as the parallel sum of two component resis-

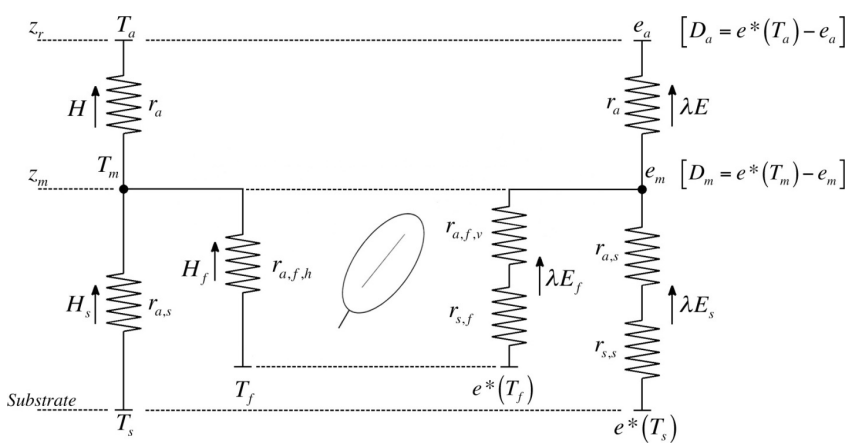

Figure 1. Resistance networks and potentials for a two-layer representation of the convective fluxes (sensible heat and latent heat) within the canopy. The nomenclature used is given in the list of symbols.

tances (see Fig. 1):

$$
\begin{aligned}
& \frac{1}{r_{\mathrm{a}, \mathrm{v}}}=\frac{1}{r_{\mathrm{a}, \mathrm{h}}}=\frac{1}{r_{\mathrm{a}, \mathrm{f}}}+\frac{1}{r_{\mathrm{a}, \mathrm{s}}}, \\
& \frac{1}{r_{\mathrm{s}, \mathrm{v}}}=\frac{1}{r_{\mathrm{s}, \mathrm{f}}}+\frac{1}{r_{\mathrm{s}, \mathrm{s}}} .
\end{aligned}
$$

Consequently, Eq. (6) can be rewritten in a simpler way as

$\lambda E=\frac{\Delta\left(R_{\mathrm{n}}-G\right)+\rho c_{p} D_{\mathrm{a}} /\left(r_{\mathrm{a}}+r_{\mathrm{a}, \mathrm{h}}\right)}{\Delta+\gamma\left(1+\frac{r_{\mathrm{s}, \mathrm{v}}}{r_{\mathrm{a}}+r_{\mathrm{a}, \mathrm{h}}}\right)}$.

This expression is similar to the traditional PenmanMonteith equation and its surface resistance expressed by Eq. (9) takes into account both foliage transpiration $\left(r_{\mathrm{s}, \mathrm{f}}\right)$ and soil surface evaporation $\left(r_{\mathrm{s}, \mathrm{s}}\right)$. Equation (10), therefore, can be considered in the one-step approach as a realistic substitute of Eq. (2) in the two-step approach. When all the air resistances within the canopy are neglected (they are generally much smaller than the surface resistances), $r_{\mathrm{a}, \mathrm{h}}=0$ and Eq. (10) adopts strictly the same form as the original Penman-Monteith equation.

\subsection{Expressing the component resistances}

The soil surface resistance $\left(r_{\mathrm{s}, \mathrm{s}}\right)$ has a clear mathematical definition based on the inversion of the equation representing the latent heat flux $\left(\lambda E_{s}\right)$ emanating from the soil surface (see Fig. 1):

$r_{\mathrm{s}, \mathrm{s}}=\left(\frac{\rho c_{p}}{\gamma}\right) \frac{\left[e^{*}\left(T_{\mathrm{s}}\right)-e_{\mathrm{S}}\right]}{\lambda E_{\mathrm{S}}}$,

where $e_{\mathrm{s}}$ is the vapour pressure at the soil surface, the other quantities are defined in the list of symbols. Its calculation, however, is rather challenging. Many parameterizations have been proposed in the literature in the form of empirical functions of near-surface soil moisture (e.g. Mahfouf and Noilhan, 1991; Sellers at al., 1992). But this issue is considered 
to be out of the scope of the present paper. Because of the stomatal characteristics of the leaves (amphi- vs. hypostomatous), the formulation of foliage resistance can be a little bit tricky and this point has been thoroughly examined by Lhomme et al. (2012). For the sake of convenience, denoting by $r_{s, l}$ the mean two-sided stomatal resistance of the leaves (per unit area of leaf), the bulk surface resistance of the foliage can be simply expressed as

$$
\frac{1}{r_{\mathrm{s}, \mathrm{f}}}=\frac{\mathrm{LAI}}{r_{\mathrm{s}, 1}}
$$

and the bulk boundary-layer resistance of the foliage (for sensible heat and water vapour) is expressed similarly

$\frac{1}{r_{\mathrm{a}, \mathrm{f}}}=\frac{\mathrm{LAI}}{r_{\mathrm{a}, 1}}$,

where $r_{\mathrm{a}, 1}$ is the leaf boundary layer per unit area of twosided leaf, calculated by Eq. (B2) in Appendix B. The air resistance between the substrate and the canopy source height $\left(r_{\mathrm{a}, \mathrm{s}}\right)$ is given by Eq. (B1) in the same appendix.

According to FAO-56, the aerodynamic resistance above the canopy $\left(r_{\mathrm{a}}\right)$ is generally calculated in neutral conditions, without stability correction functions, which is justified by the fact that the sensible heat flux is generally low under standard conditions (no water stress). It is expressed as a simple function of wind speed $u_{\mathrm{a}}$ at reference height $z_{\mathrm{r}}$ :

$r_{\mathrm{a}}=\left(\frac{1}{k^{2} u_{\mathrm{a}}}\right) \ln \left(\frac{z_{\mathrm{r}}-d}{z_{0, \mathrm{~m}}}\right) \ln \left(\frac{z_{\mathrm{r}}-d}{z_{0, \mathrm{~h}}}\right)$,

where $\quad d=0.66 z_{\mathrm{h}}, \quad z_{0, \mathrm{~m}}=0.12 z_{\mathrm{h}}, \quad z_{0, \mathrm{~h}}=z_{0, m} / 10 \quad\left(z_{\mathrm{h}}\right.$ : canopy height) and $k$ is von Karman's constant (Allen et al., 1998). However, given that the canopy roughness length for scalar $z_{0, h}$ is supposed to play the same role as the additional air resistance $r_{\mathrm{a}}$, appearing in Eq. (10), i.e. accounting for the transfer of sensible and latent heat in the air within the canopy, it would certainly be more judicious to replace $z_{0, \mathrm{~h}}$ by $z_{0, m}$ in Eq. (14), at least when the Penman-Monteith equation is interpreted in the framework of a two-layer model. It is interesting to note also that the resistance $r_{\mathrm{a}, \mathrm{h}}$ can be translated into a modified roughness length for scalar $z_{0, \mathrm{~h}}^{\prime}$ by writing the air resistance $\left(r_{\mathrm{a}}+r_{\mathrm{a}, \mathrm{h}}\right)$ in Eq. (10) in two different forms: one containing the modified roughness length and the other the additional air resistance:

$$
\begin{aligned}
& \left(\frac{1}{k^{2} u_{\mathrm{a}}}\right) \ln \left(\frac{z_{\mathrm{r}}-d}{z_{0, \mathrm{~m}}}\right) \ln \left(\frac{z_{\mathrm{r}}-d}{z_{0, \mathrm{~h}}^{\prime}}\right) \\
& =\left(\frac{1}{k^{2} u_{\mathrm{a}}}\right) \ln ^{2}\left(\frac{z_{\mathrm{r}}-d}{z_{0, \mathrm{~m}}}\right)+r_{\mathrm{a}, \mathrm{h}} .
\end{aligned}
$$

Extracting $z_{0, \mathrm{~h}}^{\prime}$ from this equation leads to

$$
z_{0, \mathrm{~h}}^{\prime}=z_{0, m} \exp \left[-\frac{k^{2} u_{\mathrm{a}} r_{\mathrm{a}, \mathrm{h}}}{\ln \left(\frac{z_{\mathrm{r}}-d}{z_{0, \mathrm{~m}}}\right)}\right] .
$$

Consequently, Eq. (10) with $r_{\mathrm{a}}$ h added to $r_{\mathrm{a}}$ can be replaced by the same equation where $r_{a, h}=0$ but where $r_{\mathrm{a}}$ is calculated by Eq. (14), $z_{0, \mathrm{~h}}^{\prime}$ replacing $z_{0, \mathrm{~h}}$. This parameter will be numerically explored below.

\section{The Matt-Shuttleworth approach extended to dual crop coefficients}

Similarly to the Matt-Shuttleworth method developed for a single crop coefficient (Shuttleworth, 2006), the problem to tackle now is to infer the values of both surface resistances $\left(r_{\mathrm{s}, \mathrm{f}}\right.$ and $\left.r_{\mathrm{s}, \mathrm{s}}\right)$, which govern respectively foliage and substrate evaporation, from those of crop coefficients $\left(K_{\mathrm{cb}}\right.$ and $K_{\mathrm{e}}$ ). As already stated, $K_{\mathrm{cb}}$ is a characteristic value of a given crop, tabulated and transferable, whereas $K_{\mathrm{e}}$ is a soil parameter adjustable to the specific conditions under which the crop is grown. Therefore, it is not really relevant to retrieve the soil surface resistance $\left(r_{\mathrm{s}, \mathrm{s}}\right)$ from $K_{\mathrm{e}}$. Nevertheless, the mathematical development being similar, it will be made for both resistances. But first, the issue of the reference height will be recalled.

\subsection{Inferring weather variables at a higher level}

Given that many crops have a crop height close to (or greater than) the reference height of $2 \mathrm{~m}$, the weather variables involved in the Penman-Monteith equation should be taken at a higher level than the reference height. This point is thoroughly developed in the Matt-Shuttleworth method, where it is suggested that air characteristics be taken at a blending height arbitrarily set at $z_{b}=50 \mathrm{~m}$ (Shuttleworth, 2006). Wind speed $\left(u_{\mathrm{b}}\right)$ at this height can be inferred from the one $\left(u_{\mathrm{a}}\right)$ at reference height $\left(z_{\mathrm{r}}\right)$ by means of the following equation based on the log-profile relationship:

$u_{\mathrm{b}}=u_{\mathrm{a}} \frac{\ln \left(\frac{z_{\mathrm{b}}-d_{0}}{z_{0 \mathrm{~m}, 0}}\right)}{\ln \left(\frac{z_{\mathrm{r}}-d_{0}}{z_{0 \mathrm{~m}, 0}}\right)}$,

where $d_{0}$ is the zero plane displacement height of the reference crop and $z_{0 \mathrm{~m}, 0}$ its roughness length for momentum. Similarly, the water vapour pressure deficit at blending height $\left(D_{\mathrm{b}}\right)$ can be expressed as a function of the one at reference height $\left(D_{\mathrm{a}}\right)$ by

$$
\begin{aligned}
& D_{\mathrm{b}}=\left(D_{\mathrm{a}}+\frac{\Delta A_{0} r_{\mathrm{a}, 0}}{\rho c_{p}}\right)\left[\frac{(\Delta+\gamma) r_{\mathrm{a}, 0, \mathrm{~b}}+\gamma r_{\mathrm{s}, 0}}{(\Delta+\gamma) r_{\mathrm{a}, 0}+\gamma r_{\mathrm{s}, 0}}\right] \\
& -\frac{\Delta A_{0} r_{\mathrm{a}, 0, \mathrm{~b}}}{\rho c_{p}}
\end{aligned}
$$

where $A_{0}=R_{\mathrm{n}, 0}-G_{0}$ is the available energy of the reference crop, $r_{\mathrm{s}, 0}$ its surface resistance, $r_{\mathrm{a}, 0}$ the aerodynamic resistance between the reference crop and the reference height, $r_{\mathrm{a}, 0, \mathrm{~b}}$ the aerodynamic resistance between the reference crop and the blending height, and $\Delta$ calculated at the reference temperature $T_{\mathrm{a}}$ (Lhomme et al., 2014, Eq. 5). 


\subsection{Retrieving the component surface resistances from crop coefficients}

Canopy evapotranspiration is the sum of foliage evaporation $\left(\mathrm{ET}_{\mathrm{f}}\right)$ and soil surface evaporation $\left(\mathrm{ET}_{\mathrm{s}}\right)$ :

$\mathrm{ET}_{\mathrm{c}}=\left(K_{\mathrm{cb}}+K_{\mathrm{e}}\right) \mathrm{ET}_{0}=\mathrm{ET}_{\mathrm{f}}+\mathrm{ET}_{\mathrm{s}}$.

The retrieval of surface resistances is obtained by expressing the two component evaporations as a function of their respective surface resistance. In the two-layer representation (Fig. 1), the component evaporations are expressed as a function of the saturation deficit $\left(D_{m}\right)$ at canopy source height $\left(z_{\mathrm{m}}=d+z_{0, \mathrm{~m}}\right)$ and the radiation load of each component ( $R_{\mathrm{n}, \mathrm{f}}$ for the foliage and $R_{\mathrm{n}, \mathrm{s}}$ for the soil surface):

$$
\begin{aligned}
\mathrm{ET}_{\mathrm{f}} & =\frac{1}{\lambda} \cdot \frac{\Delta R_{n, \mathrm{f}}+\rho c_{p} D_{m} / r_{\mathrm{a}, \mathrm{f}}}{\Delta+\gamma\left(1+\frac{r_{\mathrm{s}, \mathrm{f}}}{r_{\mathrm{a}, \mathrm{f}}}\right)}, \\
\mathrm{ET}_{\mathrm{s}} & =\frac{1}{\lambda} \cdot \frac{\Delta\left(R_{n, \mathrm{~s}}-G\right)+\rho c_{p} D_{m} / r_{\mathrm{a}, \mathrm{s}}}{\Delta+\gamma\left(1+\frac{r_{\mathrm{s}, \mathrm{s}}}{r_{\mathrm{a}, \mathrm{s}}}\right)} .
\end{aligned}
$$

The saturation deficit at canopy source height can be inferred from the one at reference height $\left(D_{\mathrm{a}}\right)$ by means of the following relationship (Shuttleworth and Wallace, 1985, Eq. 8; Lhomme et al., 2012, Eq. 7):

$$
D_{m}=D_{\mathrm{a}}+\frac{\left[\Delta\left(R_{\mathrm{n}}-G\right)-\lambda \mathrm{ET}_{\mathrm{c}}(\Delta+\gamma)\right] r_{\mathrm{a}}}{\rho c_{p}} .
$$

In fact $D_{\mathrm{a}}$ and the corresponding aerodynamic resistance $r_{\mathrm{a}}$ should be preferably replaced by those calculated at the blending height, as discussed above. Following Shuttleworth (2006), the parameter $f=R_{\mathrm{n}} / R_{\mathrm{n}, 0}$ is introduced to allow for differences in net radiation between the considered crop and the reference crop. Beer's law is used to distribute the net radiation within the canopy as a function of the leaf area index (Eqs. C5 and C6 in Appendix C).

The two surface resistances $\left(r_{\mathrm{s}, \mathrm{f}}\right.$ and $\left.r_{\mathrm{s}, \mathrm{s}}\right)$ can be retrieved from the coefficients $K_{\mathrm{cb}}$ and $K_{\mathrm{e}}$ by simply equating Eq. (20) with $K_{\mathrm{cb}} \mathrm{ET}_{0}$ and Eq. (21) with $K_{\mathrm{e}} \mathrm{ET}_{0}$, in a way similar to the Matt-Shuttleworth approach (Shuttleworth, 2006). This leads to

$$
\begin{aligned}
& r_{\mathrm{s}, \mathrm{f}}=r_{\mathrm{a}, \mathrm{f}}\left(\frac{\Delta}{\gamma}+1\right)\left[\frac{(\Delta / \gamma) R_{n, \mathrm{f}}+\frac{\rho c_{p} D_{m}}{\gamma r_{\mathrm{a}, \mathrm{f}}}}{(\Delta / \gamma+1) K_{\mathrm{cb}} \lambda \mathrm{ET}_{0}}-1\right], \\
& r_{\mathrm{s}, \mathrm{s}}=r_{\mathrm{a}, \mathrm{s}}\left(\frac{\Delta}{\gamma}+1\right)\left[\frac{(\Delta / \gamma)\left(R_{n, \mathrm{~s}}-G\right)+\frac{\rho c_{p} D_{m}}{\gamma r_{\mathrm{a}, \mathrm{s}}}}{(\Delta / \gamma+1) K_{\mathrm{e}} \lambda \mathrm{ET}_{0}}-1\right] .
\end{aligned}
$$

Reference crop evapotranspiration $\mathrm{ET}_{0}$ is calculated as usual (Eq. 3): the available energy and the aerodynamic resistance are those of the reference crop and the surface resistance $r_{\mathrm{s}, 0}$ has a fixed value of $70 \mathrm{~s} \mathrm{~m}^{-1}$, soil heat flux $(G)$ being generally neglected on a $24 \mathrm{~h}$ time step. If the air resistances within the canopy $r_{\mathrm{a}, \mathrm{f}}$ and $r_{\mathrm{a}, \mathrm{s}}$ are supposed to be negligible, Eqs. (23) and (24) transform into much simpler equations:

$r_{\mathrm{s}, \mathrm{f}}=\frac{\rho c_{p}}{\gamma} \frac{D_{m}}{K_{\mathrm{cb}} \lambda \mathrm{ET}_{0}}$,

$r_{\mathrm{s}, \mathrm{s}}=\frac{\rho c_{p}}{\gamma} \frac{D_{m}}{K_{\mathrm{e}} \lambda \mathrm{ET}_{0}}$.

These resistances should be introduced into Eq. (9) and then into the evapotranspiration formula (Eq. 10). It is important

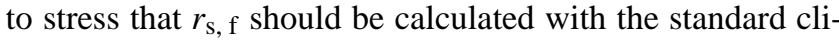
matic conditions under which the crop coefficients were obtained, whereas $r_{\mathrm{s}, \mathrm{s}}$ should be calculated with the actual conditions under which the crop is grown, which is a major difference. When there is no soil evaporation, $K_{\mathrm{e}}=0$ and $r_{\mathrm{s} \text {, s }}$ logically tends to infinite.

The fact that surface resistances are necessarily positive imposes a physical constraint on the values of $K_{\mathrm{cb}}$ and $K_{\mathrm{e}}$. These coefficients are necessarily bounded above and should verify the following inequality inferred from Eq. (22), where the saturation deficit $D_{m}$ is maintained strictly positive with $\mathrm{ET}_{\mathrm{c}}=\left(K_{\mathrm{cb}}+K_{\mathrm{e}}\right) \mathrm{ET}_{0}$ :

$K_{\mathrm{cb}}+K_{\mathrm{e}}<\frac{\lambda E_{\mathrm{p}}}{\lambda E_{0}} \quad$ with $\quad \lambda E_{\mathrm{p}}=\frac{\Delta f R_{\mathrm{n}, 0}+\rho c_{p} D_{\mathrm{a}} / r_{\mathrm{a}}}{\Delta+\gamma}$.

$\lambda E_{\mathrm{p}}$ represents the "potential" evaporation of the crop, this inequality means that, under given environmental conditions, actual crop evapotranspiration cannot be greater than its potential evaporation, which is logical.

\section{Numerical simulations and discussion}

\subsection{Preliminary considerations}

In the numerical simulations carried out below, the daily net radiation of the reference crop $\left(R_{\mathrm{n}, 0}\right)$ is estimated following Allen et al. (1998, Eqs. 37, 38 and 39) from the solar radiation taken at sea level and assumed to be at its maximum value, i.e. $75 \%$ of the extraterrestrial solar radiation $R_{\mathrm{a}}$. Leaf area index (LAI) being a parameter of the two-layer model with an evident link with the basal crop coefficient $\left(K_{\mathrm{cb}}\right)$, the empirical relationship between them proposed by Allen et al. (1998, Eq. 97), is used in the simulations:

$K_{\mathrm{cb}}=K_{\mathrm{cb}, \text { full }}[1-\exp (-0.7 \mathrm{LAI})]$.

It starts from zero for $\mathrm{LAI}=0$ with an asymptotic trend towards $K_{\mathrm{cb} \text {, full }}$ for LAI greater than 3 (for most of cereals $K_{\mathrm{cb} \text {, full }}=1.10$ according to FAO-56). This relationship is close to the one established by Duchemin et al. (2006) on wheat in Morocco. The adjustment of crop coefficient to differing climate conditions is systematically applied in the simulations using the empirical equation given in Allen et al. (1998, Eq. 62). 


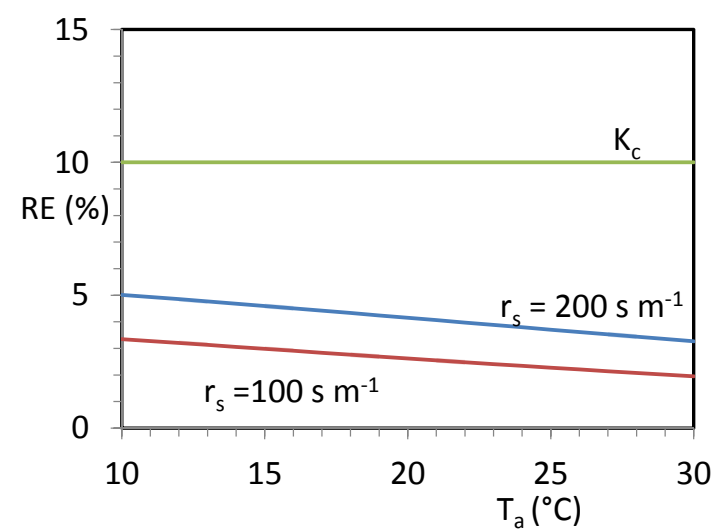

Figure 2. Relative error on crop evapotranspiration $\mathrm{ET}_{\mathrm{c}}$ $\left(\mathrm{RE}=100 \delta \mathrm{ET}_{\mathrm{c}} / \mathrm{ET}_{\mathrm{c}}\right)$ as a function of air temperature $\left(T_{\mathrm{a}}\right)$ for a $10 \%$ error on crop coefficient $K_{\mathrm{c}}$ (two-step approach) or on surface resistance $r_{\mathrm{s}}$ (one-step approach) with $z_{\mathrm{h}}=1 \mathrm{~m}$ and $u_{\mathrm{a}}=2 \mathrm{~m} \mathrm{~s}^{-1}$.

The sensitivity of crop evapotranspiration $\mathrm{ET}_{\mathrm{c}}$ to its crop parameter has been previously assessed. In the two-step approach the crop parameter is represented by the crop coefficient $K_{\mathrm{c}}$ and in the one-step approach by the surface resistance $r_{\mathrm{s}}$. The sensitivity is calculated by differentiating Eqs. (1) and (3), assuming all other variables to be accurately known. This leads respectively to

$$
\begin{aligned}
\frac{\delta \mathrm{ET}_{\mathrm{c}}}{\mathrm{ET}_{\mathrm{c}}} & =\frac{1}{K_{\mathrm{c}}} \delta K_{\mathrm{c}}, \\
\frac{\delta \mathrm{ET}_{\mathrm{c}}}{\mathrm{ET}_{\mathrm{c}}} & =\frac{-1}{(\Delta / \gamma+1) r_{\mathrm{a}}+r_{\mathrm{s}}} \delta r_{\mathrm{s}} .
\end{aligned}
$$

$\mathrm{ET}_{\mathrm{c}}$ is less sensitive to an uncertainty on $r_{\mathrm{s}}$ than on $K_{\mathrm{c}}$ as shown in Fig. 2. For a $10 \%$ error on $K_{\mathrm{c}}$, the error on $\mathrm{ET}_{\mathrm{c}}$ is $10 \%$, whereas for the same error on $r_{\mathrm{s}}(10 \%)$, the error on $\mathrm{ET}_{\mathrm{c}}$ is less than $5 \%$. This result is an additional argument in favour of the one-step approach.

\subsection{Validation of the comprehensive combination equation}

Simulations were undertaken to compare the proposed comprehensive Penman-Monteith equation (Eq. 10) with the reference model represented by the full two-layer model detailed in Appendix C. Working on a daily basis, soil heat flux is neglected and the ratio $f=R_{\mathrm{n}} / R_{\mathrm{n}, 0}$ is taken to be equal to 1 for the sake of convenience. Figure 3 shows the relative error made on crop evapotranspiration as a function of air temperature for different values of leaf area index and a fixed crop height. The relative error is less than $1 \%$ for a large range of air temperature and LAI. So, it is clear that Eq. (10) constitutes an accurate approximation of the twolayer model of evaporation, which justifies a posteriori the theoretical assumption (Eq. 7) made in deriving the formula.

As explained in Sect. 2.2, the modified roughness length $z_{0, \mathrm{~h}}^{\prime}$ (Eq. 16) can be used to calculate the aerodynamic re-
Table 1. Typical values at reference height of daily minimum relative humidity $\left(\mathrm{RH}_{\mathrm{n}, \mathrm{r}}\right)$ and of its daily mean value $\left(\mathrm{RH}_{\mathrm{m}, \mathrm{r}}\right)$ for three types of climate (from Table 16 in FAO-56).

\begin{tabular}{lrr}
\hline Climatic classification & $\mathrm{RH}_{\mathrm{n}, \mathrm{r}}(\%)$ & $\mathrm{RH}_{\mathrm{m}, \mathrm{r}}(\%)$ \\
\hline Semi-arid (SA) & 30 & 55 \\
Sub-humid (SH) & 45 & 70 \\
Humid (H) & 70 & 85 \\
\hline
\end{tabular}

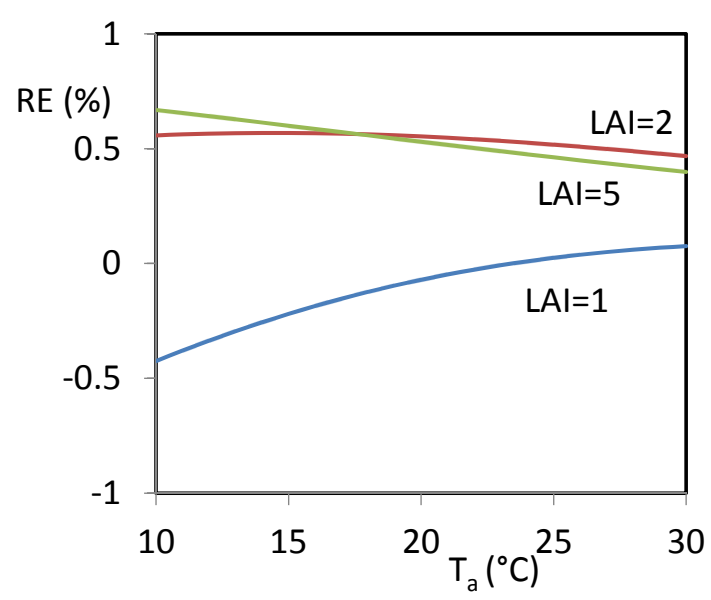

Figure 3. For different LAI, RE on crop evapotranspiration $\mathrm{ET}_{\mathrm{c}}$ when it is calculated with the modified Penman-Monteith equation (Eq. 10) compared to the two-layer model used as a reference: $z_{\mathrm{h}}=1.5 \mathrm{~m}, r_{\mathrm{s}, \mathrm{s}}=r_{\mathrm{s}, 1}=100 \mathrm{~m} \mathrm{~s}^{-1}$, under sub-humid conditions with $u_{\mathrm{a}}=2 \mathrm{~m} \mathrm{~s}^{-1}$ and $R_{\mathrm{a}}=40 \mathrm{MJ} \mathrm{m}^{-2} \mathrm{~d}^{-1}$.

sistance $r_{\mathrm{a}}$ in Eq. (10), replacing the additional resistance $r_{\mathrm{a}, \mathrm{h}}$; it is essentially a function of wind speed and crop structural characteristics (LAI and height). Figure 4 shows how the ratio $z_{0, \mathrm{~h}}^{\prime} / z_{0, \mathrm{~m}}$ varies as a function of crop height and wind speed for a fixed LAI (3): it decreases slightly with crop height and more strongly with wind speed, ranging approximately between 0.1 and 0.4 . These values are slightly higher than the value of 0.1 commonly used in the FAO-56 calculation of the aerodynamic resistance (Eq. 14). In future, simple statistical parameterizations of this ratio could be developed to facilitate its use in the calculation of the aerodynamic resistance.

\subsection{Inferring surface resistance from crop coefficient}

Foliage surface resistance $r_{\mathrm{s} \text {, f }}$ can be inferred from the tabulated value of the basal crop coefficient $K_{\mathrm{cb}}$ by means of Eq. (23) or (25). The tabulated value is supposed to be valid under sub-humid conditions and should be corrected under other conditions, as previously mentioned. Inferring soil surface resistance $r_{\mathrm{s}, \mathrm{s}}$ from soil evaporation coefficient $K_{\mathrm{e}}$ by means of Eq. (24) or (26) is not really relevant since $K_{\mathrm{e}}$ is not a tabulated value. Numerical explorations are carried out under different conditions of air temperature and humidity 


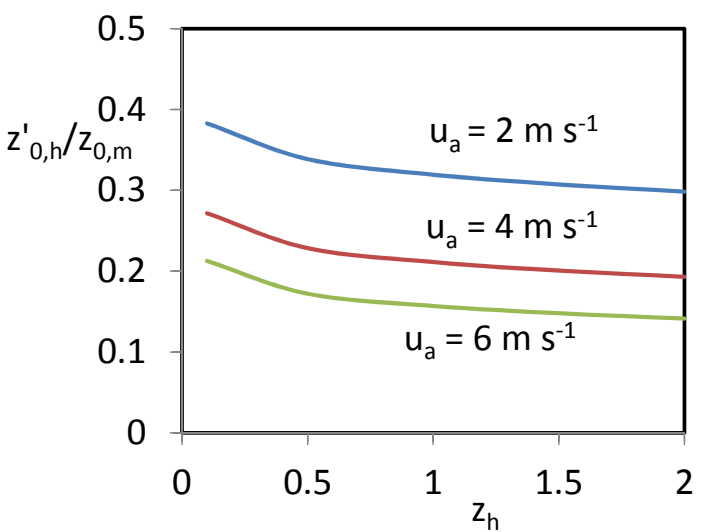

Figure 4. Variation of the ratio between the modified roughness length $\left(z_{0, \mathrm{~h}}^{\prime}\right)$ and the roughness length for momentum $\left(z_{0, \mathrm{~m}}\right)$ as a function of crop height $\left(z_{\mathrm{h}}\right)$ for different wind speeds at the reference height $\left(u_{\mathrm{a}}\right)$ and $\mathrm{LAI}=3$.

Table 2. For three types of climate (SA, SH, $H$ ) and three different temperatures, relative error made on the value of foliage surface resistance $\left(r_{\mathrm{s}, \mathrm{f}}\right)$, as inferred from the basal crop coefficient $\left(K_{\mathrm{cb}}\right)$, when calculated with the simplified formula (Eq. 25) compared to the comprehensive formula (Eq. 23). $K_{\mathrm{cb}}=0.9, K_{\mathrm{e}}=0.1$, $z_{\mathrm{h}}=1 \mathrm{~m}, u_{\mathrm{a}}=2 \mathrm{~m} \mathrm{~s}^{-1}, R_{\mathrm{a}}=35 \mathrm{~W} \mathrm{~m}^{-2}$.

\begin{tabular}{lrrr}
\hline & \multicolumn{3}{c}{ Air temperature } \\
\cline { 2 - 4 } & $10^{\circ} \mathrm{C}$ & $20^{\circ} \mathrm{C}$ & $30^{\circ} \mathrm{C}$ \\
\hline SA & $3 \%$ & $4 \%$ & $6 \%$ \\
SH & $0 \%$ & $1 \%$ & $2 \%$ \\
$\mathrm{H}$ & $-7 \%$ & $-5 \%$ & $5 \%$ \\
\hline
\end{tabular}

following FAO-56 (Table 16 and Fig. 32), where three types of climate are defined as a function of their relative humidity (Table 1). Figure 5 shows, for these three climatic environments, how the foliage surface resistance $\left(r_{\mathrm{s}, \mathrm{f}}\right)$, inferred from the basal crop coefficient $\left(K_{\mathrm{cb}}\right)$, varies as a function of air temperature. Two contrasting cases are considered with the assumption $f=1$ : one representing the initial stage of an annual crop with $z_{\mathrm{h}}=0.5 \mathrm{~m}$ and $K_{\mathrm{cb}}=0.5$ (Fig. 5a) and the other case, with $z_{\mathrm{h}}=1.5 \mathrm{~m}$ and $K_{\mathrm{cb}}=1.0$, representing the mid-season stage (Fig. 5b). These figures clearly show that crop coefficients cannot be easily translated into surface resistances because of the interference of climate characteristics such as air temperature and humidity (as shown here), but also wind speed and solar radiation (not shown) and other factors such as the soil evaporation coefficient $\left(K_{\mathrm{e}}\right)$. Table 2 exemplifies for a typical crop and different climatic conditions the relative error made on the value of $r_{\mathrm{s}, \mathrm{f}}$ when the simplified formulation (Eq. 25) is used instead of the comprehensive one (Eq. 23). The relative error is generally lower than $10 \%$ and much less under sub-humid conditions (around $1 \%$ ), which justifies the use of the simplified formula as an accurate approximation.
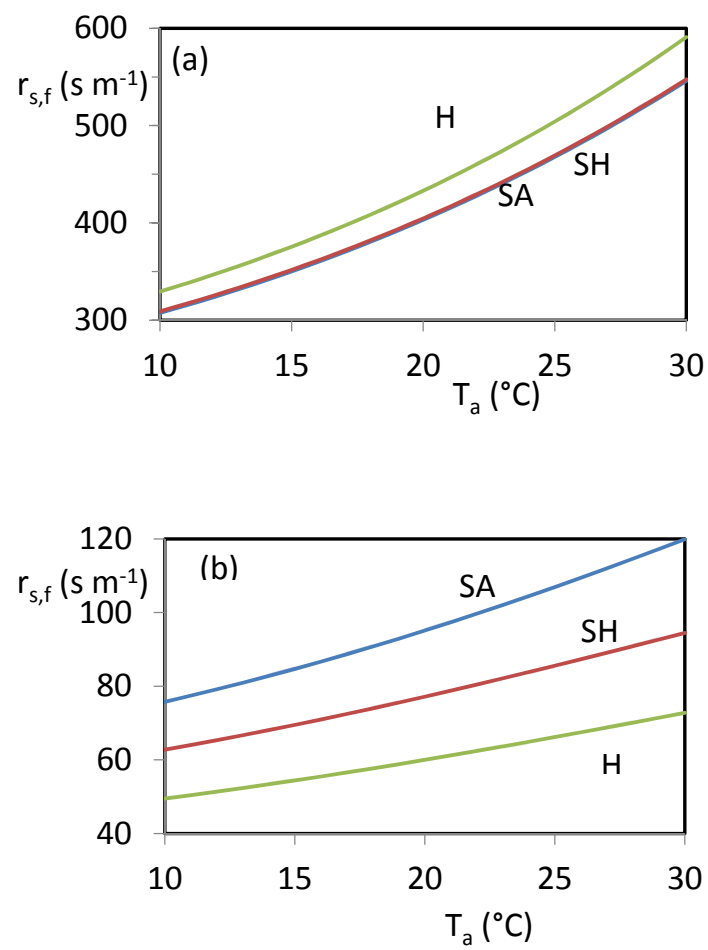

Figure 5. Variation of foliage surface resistance $\left(r_{\mathrm{s}, \mathrm{f}}\right)$ inferred from the basal crop coefficient $\left(K_{\mathrm{cb}}\right)$ as a function of air temperature $\left(T_{\mathrm{a}}\right)$ for the three climatic environments (SA: semi-arid; $\mathrm{SH}$ : sub-humid; $H$ : humid) described in Table 1 with $u_{\mathrm{a}}=2 \mathrm{~m} \mathrm{~s}^{-1}$, $R_{\mathrm{a}}=35 \mathrm{MJ} \mathrm{m}^{-2} \mathrm{~d}^{-1}$ and $K_{\mathrm{e}}=0.1$ : (a) initial stage, $z_{\mathrm{h}}=0.5 \mathrm{~m}$, $K_{\mathrm{cb}}=0.5$; (b) mid-season stage, $z_{\mathrm{h}}=1.5 \mathrm{~m}, K_{\mathrm{cb}}=1$.

\section{Conclusion and perspectives}

We have shown that the FAO-56 dual crop coefficient approach, where the crop coefficient $K_{\mathrm{c}}$ is split into two separate coefficients (one for crop transpiration and another for soil evaporation), can be easily translated into a onestep approach based upon a Penman-Monteith type equation (Eq. 10), its surface resistance being the parallel sum of a soil and foliage resistance. This new form of the PenmanMonteith equation estimates fairly accurately crop evapotranspiration when compared to a full two-layer model. It is also much less sensitive to an error on the crop parameter (represented by the surface resistance) than the FAO-56 methodology based on the crop coefficient. We have also shown that the foliage resistance of the one-step approach can be inferred from the crop coefficients $\left(K_{\mathrm{cb}}\right.$ and $\left.K_{\mathrm{e}}\right)$ in a way similar to the Matt-Shuttleworth method. The interference of environmental factors, however, makes the calculation somewhat hazardous.

As a consequence of the above development, and following the suggestion already made by Shuttleworth (2014) for computing crop water requirements, we think that the United Nations FAO could find some interest in recommending the use of the one-step approach in replacement of the FAO-56 
two-step approach. In the one-step approach, four parameters should be adjusted to a specific crop: its albedo to estimate the net radiation, its aerodynamic resistance and the two components of the surface resistance (soil and vegetation). Albedo varies as a function of green canopy cover (or LAI). The aerodynamic resistance is calculated as a function of crop height (Eq. 14), provided the roughness length is correctly determined (Eq. 16). The soil component of the surface resistance requires a specific parameterization as a function of top soil layer water content. Some empirical parameterizations already exist and should be thoroughly examined and tested. With regard to foliage resistance, although it can be inferred in principle from the basal crop coefficient, it is certainly more recommendable to undertake experimental and bibliographical works in order to determine appropriate values under standard conditions (i.e. non-stressed and wellmanaged crop). Given that foliage resistance is expressed as the simple ratio of leaf stomatal resistance to leaf area (see Eq. 12) and that LAI is an adjustable and experimentally accessible parameter, one can imagine that the mean leaf stomatal resistance could play the same role in the onestep approach as (and replace) the basal crop coefficient of the two-step approach. Tabulated values for different crops could be supplied and organized by group type in the same way as the crop coefficients in FAO-56. Only one value per crop could be needed, instead of the three values generally provided for crop coefficients, given that LAI values should be able to account for the necessary adjustment to crop cycle characteristics. It is worthwhile stressing, nevertheless, that the leaf stomatal resistance of a given crop under standard conditions (which represents a minimum value) is subject to the influence of other climatic environment parameters than water stress (i.e. temperature, humidity, radiation, $\mathrm{CO}_{2}$; Jarvis, 1976): its value should be specific to a particular environment and adjustable to other conditions by means of appropriate formulae. 
Appendix A: Calculation of the coefficient for soil evaporation $\left(\mathbf{K}_{e}\right)$

According to FAO-56, the daily calculation of $K_{\mathrm{e}}$ is the result of a relatively complex procedure based on Eq. (A1):

$K_{\mathrm{e}}=\min \left[K_{\mathrm{r}}\left(K_{\mathrm{c}, \max }-K_{\mathrm{cb}}\right), f_{\mathrm{ew}} K_{\mathrm{c}, \max }\right]$,

where $K_{\mathrm{cb}}$ is the basal crop coefficient, $K_{\mathrm{c}, \max }$ is the maximum value of $K_{\mathrm{c}}=K_{\mathrm{cb}}+K_{\mathrm{e}}$ following rain or irrigation, and $K_{\mathrm{r}}$ is a dimensionless coefficient for the reduction of evaporation due to the depletion of water from the top soil. Its practical calculation relies on a daily water balance computation for the surface soil layer detailed in FAO-56. $f_{\mathrm{ew}}$ is the fraction of soil surface from which most evaporation occurs. Its calculation is also detailed in FAO-56. $K_{\mathrm{c}, \max }$ is obtained from the following empirical equation:

$K_{\mathrm{c}, \max }$

$=\max \left[\left\{1.2+\left[0.04\left(u_{2}-2\right)-0.004\left(\mathrm{RH}_{\min }-45\right)\right]\left(\frac{z_{\mathrm{h}}}{3}\right)^{0.3}\right\}\right.$,

$\left.\left\{K_{\mathrm{cb}}+0.05\right\}\right]$,

where $u_{2}$ is the mean wind speed at $2 \mathrm{~m}$ height over grass and $\mathrm{RH}_{\min }$ is the mean minimum relative humidity. 
Table A1. List of symbols.

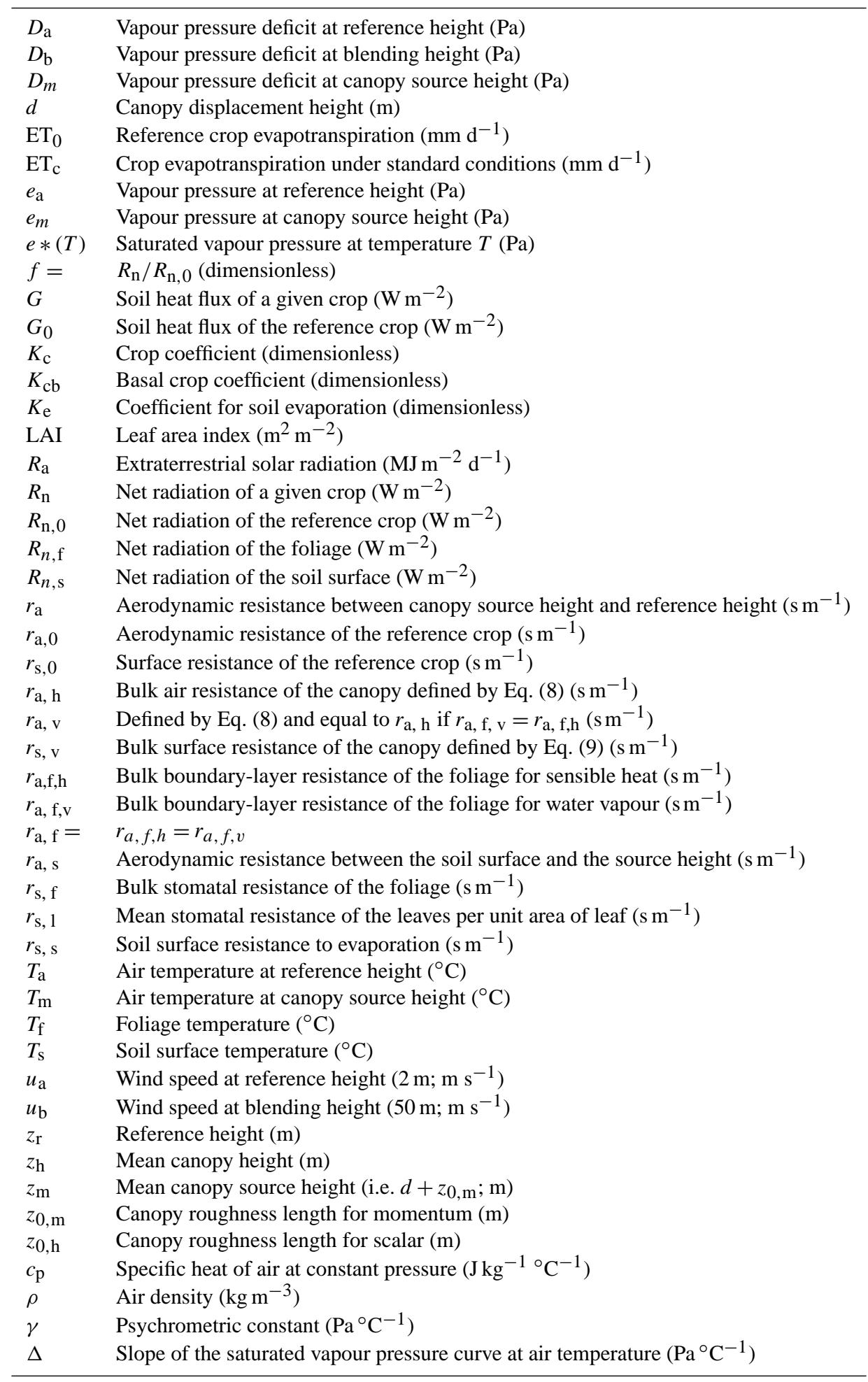


Appendix B: Parameterization of air resistances within the canopy

The parameterization commonly used to simulate the component air resistances taken and adapted from Shuttleworth and Wallace (1985), Choudhury and Monteith (1988), Shuttleworth and Gurney (1990), Lhomme et al. (2012). The aerodynamic resistance between the substrate (with a roughness length $z_{0, \mathrm{~s}}$ of $0.01 \mathrm{~m}$ ) and the canopy source height $\left(d+z_{0, \mathrm{~m}}\right)$ is calculated as the integral of the reciprocal of eddy diffusivity over the height range $\left[z_{0, \mathrm{~s}}, d+z_{0, \mathrm{~m}}\right]$ :

$$
\begin{aligned}
& r_{\mathrm{a}, \mathrm{s}}=\frac{z_{\mathrm{h}} \exp \left(\alpha_{w}\right)}{\alpha_{w} K\left(z_{\mathrm{h}}\right)}\left\{\exp \left[-\alpha_{w} z_{0, \mathrm{~s}} / z_{\mathrm{h}}\right]\right. \\
& \left.-\exp \left[-\alpha_{w}\left(d+z_{0, \mathrm{~m}}\right) / z_{\mathrm{h}}\right]\right\},
\end{aligned}
$$

where $z_{\mathrm{h}}$ is the canopy height, $\alpha_{w}=2.5$ (dimensionless) and $K\left(z_{\mathrm{h}}\right)$ is the value of eddy diffusivity at canopy height. With the assumption that leaf area is uniformly distributed with height, the leaf boundary-layer resistance (two sides) per unit area of leaf is expressed as a function of wind speed at canopy height $u\left(z_{\mathrm{h}}\right)$ as

$$
r_{a, l}=\frac{\alpha_{w}\left[w / u\left(z_{\mathrm{h}}\right)\right]^{1 / 2}}{4 \alpha_{0}\left[1-\exp \left(-\frac{\alpha_{w}}{2}\right)\right]},
$$

$w$ is leaf width $(0.03 \mathrm{~m})$ and $\alpha_{0}$ is a constant equal to 0.005 (in $\mathrm{m} \mathrm{s}^{-1 / 2}$ ). The eddy diffusivity at canopy height is expressed as $K\left(z_{\mathrm{h}}\right)=k^{2} u_{\mathrm{a}}\left(z_{\mathrm{h}}-\mathrm{d}\right) / \ln \left[\left(z_{\mathrm{r}}-d\right) / z_{0}\right]$ and the corresponding wind speed $u\left(z_{\mathrm{h}}\right)$ is obtained from an equation similar to Eq. (17). 


\section{Appendix C: Formulations of the two-layer model}

Following the reformulated expression of the two-layer model proposed by Lhomme et al. (2012), crop evaporation is given by

$$
\begin{aligned}
& \lambda E=\left(1+\frac{\Delta}{\gamma}\right)\left(P_{\mathrm{f}}+P_{\mathrm{s}}\right) \lambda E_{\mathrm{p}} \\
& +\frac{\left(\frac{\Delta}{\gamma}\right)\left(P_{\mathrm{f}} R_{n, \mathrm{f}} r_{\mathrm{a}, \mathrm{f}}+P_{\mathrm{s}}\left(R_{n, \mathrm{~s}}-G\right) r_{\mathrm{a}, \mathrm{s}}\right)}{r_{\mathrm{a}}}
\end{aligned}
$$

where $\lambda E_{\mathrm{p}}$ represents the potential evaporation expressed as

$\lambda E_{\mathrm{p}}=\frac{\Delta\left(R_{\mathrm{n}}-G\right)+\frac{\rho c_{p} D_{\mathrm{a}}}{r_{\mathrm{a}}}}{\Delta+\gamma}$.

The resistive terms are defined as follows:

$P_{\mathrm{f}}=\frac{r_{\mathrm{a}} R_{\mathrm{s}}}{R_{\mathrm{f}} R_{\mathrm{S}}+R_{\mathrm{a}} R_{\mathrm{f}}+R_{\mathrm{a}} R_{\mathrm{S}}}$,

$P_{\mathrm{s}}=\frac{r_{\mathrm{a}} R_{\mathrm{f}}}{R_{\mathrm{f}} R_{\mathrm{s}}+R_{\mathrm{a}} R_{\mathrm{f}}+R_{\mathrm{a}} R_{\mathrm{s}}}$,

with

$R_{\mathrm{a}}=\left(1+\frac{\Delta}{\gamma}\right) r_{\mathrm{a}}, R_{\mathrm{f}}=r_{s, f}+\left(1+\frac{\Delta}{\gamma}\right) r_{\mathrm{a}, \mathrm{f}}$,

$R_{\mathrm{S}}=r_{s, s}+\left(1+\frac{\Delta}{\gamma}\right) r_{\mathrm{a}, \mathrm{s}}$.

Net radiation $R_{\mathrm{n}}$ is partitioned between the foliage and the soil surface as a function of the LAI following Beer's law:

$R_{n, \mathrm{~s}}=R_{\mathrm{n}} \exp (-\alpha \mathrm{LAI})$,

$R_{\mathrm{n}, \mathrm{f}}=R_{\mathrm{n}}[1-\exp (-\alpha \mathrm{LAI})]$.

A typical value of the attenuation coefficient is $\alpha=0.6$. Soil heat fluxes $(G)$ are generally neglected on a $24 \mathrm{~h}$ time step. 
Edited by: N. Romano

\section{References}

Allen, R. G.: Using the FAO-56 dual crop coefficient method over an irrigated region as part of an evapotranspiration intercomparison study, J. Hydrol., 229, 27-41, 2000.

Allen, R. G., Pereira, L. S., Raes, D., and Smith, M.: Crop evapotranspiration, Irrig. Drainage Paper No 56, United Nations FAO, Rome, 300 pp., 1998.

Choudhury, B. J. and Monteith, J. L.: A four-layer model for the heat budget of homogeneous land surfaces, Q. J. Roy. Meteor. Soc., 114, 373-398, 1988.

Doorenbos, J. and Pruitt, W. O.: Guidelines for predicting crop water requirements, FAO Irrigation and Drainage Paper no. 24. FAO, Rome, 144 pp., 1977.

Duchemin, B., Hadria, R., Erraki, S., Boulet, G., Maisongrande, P., Chehbouni, A., Escadafal, R., Ezzahar, J., Hoedjes, J. C. B., Kharrou, M. H., Khabba, S., Mougenot, B., Olioso, A., Rodriguez, J. C., and Simonneaux, V.: Monitoring wheat phenology and irrigation in Central Morocco: on the use of relationships between evapotranspiration, crop coefficients, leaf area index and remotely-sensed vegetation indices, Agric. Water. Manage., 79, 1-27, 2006.

Jarvis, P. G.: The interpretation of leaf water potential and stomatal conductance found in canopies in the field, Phil. Trans. R. Soc. London, Ser. B, 273, 593-610, 1976.

Katerji, N. and Rana, G.: FAO-56 methodology for determining water requirements of irrigated crops: critical examination of the concepts, alternative proposals and validation in Mediterranean region, Theor. Appl. Climatol., 116, 515-536, 2014.

Lhomme, J. P., Montes, C., Jacob, F., and Prévot, L.: Evaporation from heterogeneous and sparse canopies: on the formulations related to multi-source representations, Bound.-Lay. Meteorol., 144, 243-262, 2012.

Lhomme, J. P., Boudhina, N., and Masmoudi, M. M.: Technical Note: On the Matt-Shuttleworth approach to estimate crop water requirements, Hydrol. Earth Syst. Sci., 18, 4341-4348, doi:10.5194/hess-18-4341-2014, 2014.
Mahfouf, J. F. and Noilhan, J.: Comparative study of various formulations of evaporation from bare soil using in-situ data, J. Appl. Meteorol., 30, 1354-1365, 1991.

Monteith, J. L.: Gas exchange in plant communities, in: Environmental Control of Plant Growth, edited by: Evans, L. T., Academic Press, New York, 95-112, 1963.

Monteith, J. L.: Evaporation and the environment, Symp. Soc. Experimental Biology, 19, 205-234, 1965.

Rosa, R. D., Paredes, P., Rodrigues, G. C., Alves, I., Fernando, R. M., Pereira, L. S., and Allen, R. G.: Implementing the dual crop coefficient approach in interactive software, 1. Background and computational strategy, Agric. Water Manage., 103, 8-24, 2012.

Sellers, P. J., Heiser, M. D., and Hall, F. G.: Relations between surface conductance and spectral vegetation indices at intermediate $\left(100 \mathrm{~m}^{2}\right.$ to $\left.15 \mathrm{~km}^{2}\right)$ length scales, J. Geophys. Res., 97,19033 19059, 1992.

Shuttleworth, W. J.: Towards one-step estimation of crop water requirements, T. ASABE, 49, 925-935, 2006.

Shuttleworth, W. J. and Wallace, J. S.: Calculating the water requirements of irrigated crops in Australia using the Matt-Shuttleworth approach, T. ASABE, 52, 1895-1906, 2009.

Shuttleworth, W. J.: Putting the "vap" into evaporation, Hydrol. Earth Syst. Sci., 11, 210-244, doi:10.5194/hess-11-210-2007, 2007.

Shuttleworth, W. J.: Comment on "Technical Note: On the MattShuttleworth approach to estimate crop water requirements" by Lhomme et al. (2014), Hydrol. Earth Syst. Sci., 18, 4403-4406, doi:10.5194/hess-18-4403-2014, 2014.

Shuttleworth, W. J. and Gurney, R. J.: The theoretical relationship between foliage temperature and canopy resistance in sparse crops, Q. J. Roy. Meteorol. Soc., 116, 497-519, 1990.

Shuttleworth, W. J. and Wallace, J. S.: Evaporation from sparse crops-an energy combination theory, Q. J. Roy. Meteorol. Soc. 111, 839-855, 1985.

Wallace, J. S.: Calculating evaporation: resistance to factors, Agric. Forest Meteorol., 73, 353-366, 1995. 